\title{
Allergic Contact Dermatitis
}

National Cancer Institute

\section{Source}

National Cancer Institute. Allergic Contact Dermatitis. NCI Thesaurus. Code C26998.

An inflammatory skin condition caused by an immune response to direct contact

between the skin and an allergen. It consists of a delayed type of allergic reaction at the affected site with resulting red, swollen, and blistered skin that may itch or leak. 